\title{
The X-Ray Photoelectron Spectroscopy of Copper Complxes in the Interlayer Space of Clay Minerals
}

\author{
Yoshiko YANO, Masayuki NAKANO and Daisuke TAKAKURA \\ Department of Chemical Science and Engineering, Tokyo National College of Technology,
} Hachioji, Tokyo193, JAPAN

\begin{abstract}
X-ray photoelectron spectroscopy (XPS) was used to characterize the copper ion of 1,10-phenanthroline (phen) complexes in the interlayer space of natural montmorillonite and artificial saponite. $\left[\mathrm{Cu}(\mathrm{phen})_{2}\right]^{2+}$ and $\left[\mathrm{Cu}(\mathrm{phen})_{3}\right]^{2+}$ were intercalated into the minerals instead of ion-exchangeable cations occupying the original interlayer space. Loading amount of complex can be varied up to $170 \%$ of cation exchange capacity (CEC) of each clay minerals. Cu(II) $2 \mathrm{p}$ photopeakes of $\left[\mathrm{Cu}(\mathrm{phen})_{2}\right]^{2+}$ and $\left[\mathrm{Cu}(\mathrm{phen})_{3}\right]^{2+}$ in saponite remarkably decrease as loading amount decreases from 170 to $50 \%$, while $\mathrm{Cu}(\mathrm{I})$ photopeaks increase by photoreduction. X-ray diffraction (XRD) indicated that there was sufficient space to exist $\left[\mathrm{Cu}(\mathrm{phen})_{2}\right]^{2+}$ without any distortion at $170 \%$. In montmorillonite, there is sufficient space even at $50 \%$ of $\mathrm{CEC}$ for $\left[\mathrm{Cu}(\mathrm{phen})_{3}\right]^{2+}$ and $\left[\mathrm{Cu}(\mathrm{phen})_{2}\right]^{2+}$. XPS spectra suggest two or more binding state of the complexes at interlayer space of montmorillonite.
\end{abstract}

Keywords XPS, copper complex, phenanthroline, photoreduction

Clay minerals are layered phyllosilicate minerals having cation exchange properties. Some metal chelate cations are absorbed by them. Studies on tris (phenanthroline)metal(II) in clay minerals have been reported 1.4 from vari ous view points. An ESR study 1 suggests that there are two absorptopion states of tris(phenan throline)copper(II), $\left[\mathrm{Cu}(\mathrm{phen})_{3}\right]^{2+}$, in interlayer space of hectorite. The structure of an intercalated complex cation on a binding state is distorted when phyllosilicate layers interact each other strongly. Even a change of chemical state of copper ion would be caused $t h$ rough the distortion. In present study $\mathrm{X}$-ray photoelectron spectroscopy (XPS) of $\left[\mathrm{Cu}(\text { phen })_{3}\right]^{2+}$ and $\left[\mathrm{Cu}(\text { phen })_{2}\right]^{2+}$ in clay mi nerals are investigated. XPS is useful for characterization of the chemical state of copper ion.5-7 Two different clay minerals will be used, montmorillonite and saponite. Each of them has similar phyllosilicate layers as Fig. 1 shows. The difference between them is as follows. The tet rahedral metal site ( $T$-) of the layer is occupied only by $\mathrm{Si}$ in montmorillonite, while by $\mathrm{Al}$ and $\mathrm{Si}$ in saponite. Two thirds of octahedral metal site $\left(\mathrm{O}^{-}\right)$is occupied by $\mathrm{Al}$ and $\mathrm{Mg}$ in montmorillonite, while only Mg occupies whole octahedral site in saponite. What the difference means is that negative charge of phyllosilicate layer is induced at inner octahedral site of montmorillonite and that it is induced at outer tetrahedral site of saponite.

\section{Experimental}

\section{Copper(II) and (I) complexes}

Three Copper complexes, $\left[\mathrm{Cu}(\text { phen })_{3}\right]\left(\mathrm{NO}_{3}\right)_{2} \cdot 2 \mathrm{H}_{2} \mathrm{O}$, $\left[\mathrm{Cu}(\text { phen })_{2}\right]\left(\mathrm{NO}_{3}\right)_{2} \cdot \mathrm{H}_{2} \mathrm{O}$ and $\left[\mathrm{Cu}(\text { phen })_{2}\right]_{2}\left(\mathrm{SO}_{4}\right) \cdot$

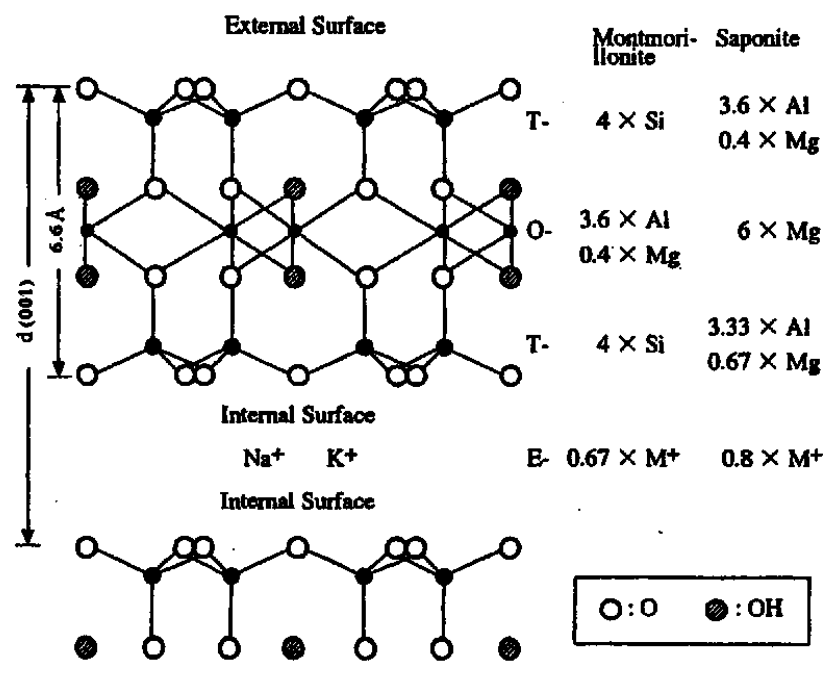

Fig. 1 Structure of typical montmorillonite and saponite. A pillosilicate layer consists of three sub-layers. Outer two hav e tetrahedral metal site, denoted by $T_{-}$, and octahedral site, denoted by $O$ - is between them. 


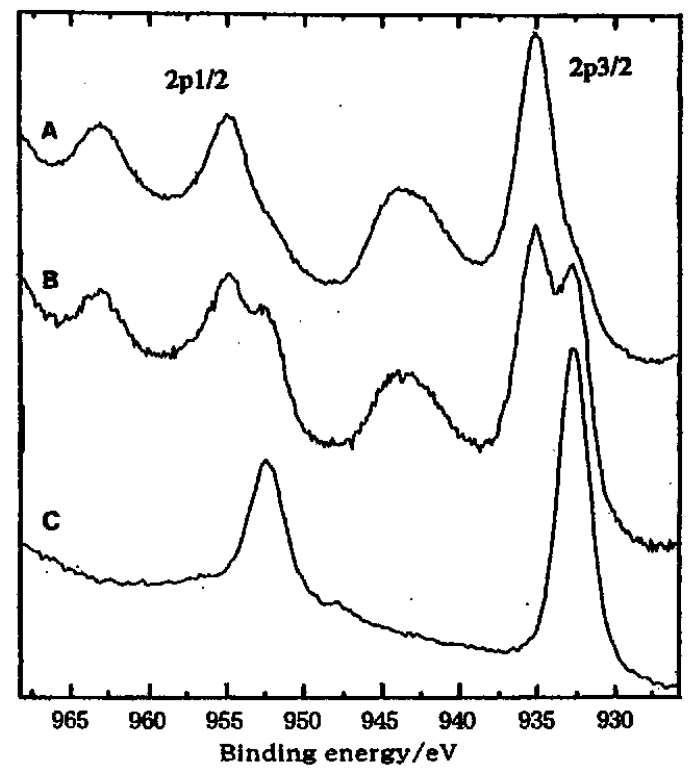

Fig. 2 XPS spectra of the $\mathrm{Cu} 2 \mathrm{p}$ for $\mathrm{A}$ : $\left[\mathrm{Cu}(\mathrm{phen})_{2}\right]\left(\mathrm{NO}_{3}\right)_{2}$. $\mathrm{H}_{2} \mathrm{O}$, B: [Cu(phen $\left.)_{3}\right]\left(\mathrm{NO}_{3}\right)_{2} \cdot 2 \mathrm{H}_{2} \mathrm{O}$ and $\mathrm{C}$ : [Cu(I)(phen) $\left.{ }_{2}\right]\left(\mathrm{SO}_{4}\right) \cdot 2 \mathrm{H}_{2} \mathrm{O}$.

$2 \mathrm{H}_{2} \mathrm{O}$, were prepared by reported procedures ${ }^{8}$. They were characterized by elemental analysis of $\mathrm{C}$, $\mathrm{H}$, and $\mathrm{N}$.

\section{Clay minerals}

Refined natural montmorillonite and synthetic saponite were provided by Kunimine Ind. Co., Japan. The cation exchange capacity (CEC) of montmorillonite and saponite are stated to be 119 and $80.2 \mathrm{meq} / 100 \mathrm{~g}$, respectively.

\section{Procedure of intercalation of copper complexes}

Colloidal solution of a clay mineral of $1 \%$ and aqueous solution of a copper complex were prepared. Same volume of both solutions were mixed and stirred drop by drop and the resultant mixed solution was continuously stirred for 4 days. Clay mineral with $\mathrm{Cu}$ complex was separated as gelatinous phase and it was centrifuged by $10,000 \mathrm{rpm}$ for 1 hour. The gel was freeze-dried. The loading amount of a $\mathrm{Cu}$ complex was adjusted by the concentration of the complex solution used. The values of the loading amount were experimentally determined by UV spectrometry of residual amount of complex in the supernatant solution after centrifugal separation.

\section{$X P S:$}

The instrument used was ULVAC-PHI-5600 model with $\mathrm{X}$-ray source of $\mathrm{Al}-\mathrm{K} \alpha$ at $150 \mathrm{~W}$ typically. The $\mathrm{Cu}$ $2 p_{3 / 2}$ and $2 p_{1 / 2}$ photopeaks were observed. Acquisition time of XPS was $20 \mathrm{~min}$., unless effect of exposure time to $\mathrm{X}$-ray was investigated.

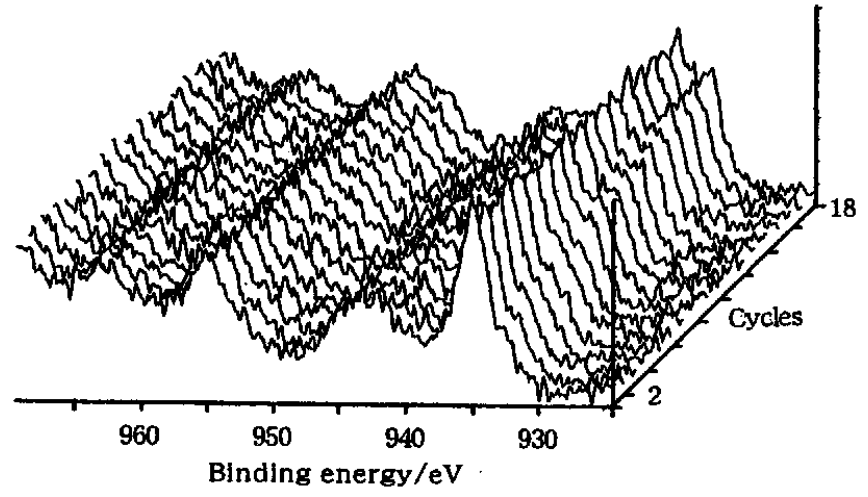

Fig. 3 Time dependent XPS profile of $\mathrm{Cu} 2 \mathrm{p}$ for $\left[\mathrm{Cu}(\mathrm{phen})_{2}\right]-$ $\left(\mathrm{NO}_{3}\right)_{2} \cdot \mathrm{H}_{2} \mathrm{O}$. Acquisition time of each cycle is $1 / 18$ hour.

\section{$X$-ray diffraction $(X R D)$}

The basal $d(001)$ spacing of clay minerals was determined by powder XRD. Silicon d(111) peak was used as a standard of spacing.

\section{Results and Discussion}

\section{Copper(II) and (I) complexes}

XPS spectra of $\mathrm{Cu} 2 \mathrm{p}$ of all samples investigated show photoreduction effect in present study except for a $\mathrm{Cu}(\mathrm{I})$ complex.

Figure 2 is the spectra for $\left[\mathrm{Cu}(\text { phen })_{2}\right]\left(\mathrm{NO}_{3}\right)_{2} \cdot \mathrm{H}_{2} \mathrm{O}$, $\left[\mathrm{Cu}(\text { phen })_{3}\right]\left(\mathrm{NO}_{3}\right)_{2} \cdot 2 \mathrm{H}_{2} \mathrm{O}$, and $\left[\mathrm{Cu}(\mathrm{I})(\text { phen })_{2}\right]\left(\mathrm{SO}_{4}\right) \cdot$ $2 \mathrm{H}_{2} \mathrm{O}$. The first complex gives typical lines for $\mathrm{Cu}(\mathrm{II})$ (Fig. 2, A). Both $2 p_{3 / 2}$ and $2 p_{1 / 2}$ core lines consist of two components. Peak at binding energy of $935 \mathrm{eV}$ is accompanied by a satellite peak at $943 \mathrm{eV}$, and peak at $955 \mathrm{eV}$ by $963 \mathrm{eV}$. No photoreduction effect seems to be observed. After 1 hour irradi ation of X-ray, however, a photoreduction effect was recognized for the complex as Fig. 3 shows. $\quad \mathrm{Cu}(\mathrm{I}) 2 \mathrm{p}_{3 / 2}$ peak grows as $\mathrm{X}$ ray irradiation cycles increase. Though, its relative intensity seemed to reach a constant value. It probably means there is a $\mathrm{Cu}$ (II) $\rightleftarrows \mathrm{Cu}$ (I) equilibrium. ${ }^{5}$ After long X-ray irradiation the complex lost its original color of green and became deep violet which is the color of corresponding $\mathrm{Cu}(\mathrm{I})$ complex. $\mathrm{Cu}(\mathrm{I})$ complex gives a peak at $932.5 \mathrm{eV}$ for $2 \mathrm{p}_{3 / 2}$ and at $952.5 \mathrm{eV}$ for $2 \mathrm{p}_{1 / 2}$ (Fig. $2 \mathrm{C}$ ). These are typical for $\mathrm{Cu}(\mathrm{I})$. The spectrum for $\left[\mathrm{Cu}(\text { phen })_{3}\right]\left(\mathrm{NO}_{3}\right)_{2} \cdot 2 \mathrm{H}_{2} \mathrm{O}$ shows a photoreduction effect (Fig. $2 \mathrm{~B}$ ) . Both $2 \mathrm{p}_{3 / 2}$ and $2 \mathrm{p}_{1 / 2}$ core lines consist of three components. $\mathrm{Cu}$ (II) and $\mathrm{Cu}$ (I) line are superimposed. $\mathrm{Cu}$ (II) complexes mentioned above and their cations, $\left[\mathrm{Cu}(\text { phen })_{3}\right]^{2+}$, and $\left[\mathrm{Cu}(\text { phen })_{2}\right]^{2+}$ are hereafter denoted as $\operatorname{Cu} \varnothing_{3}$ and $\operatorname{Cu} \varnothing_{2}$. 


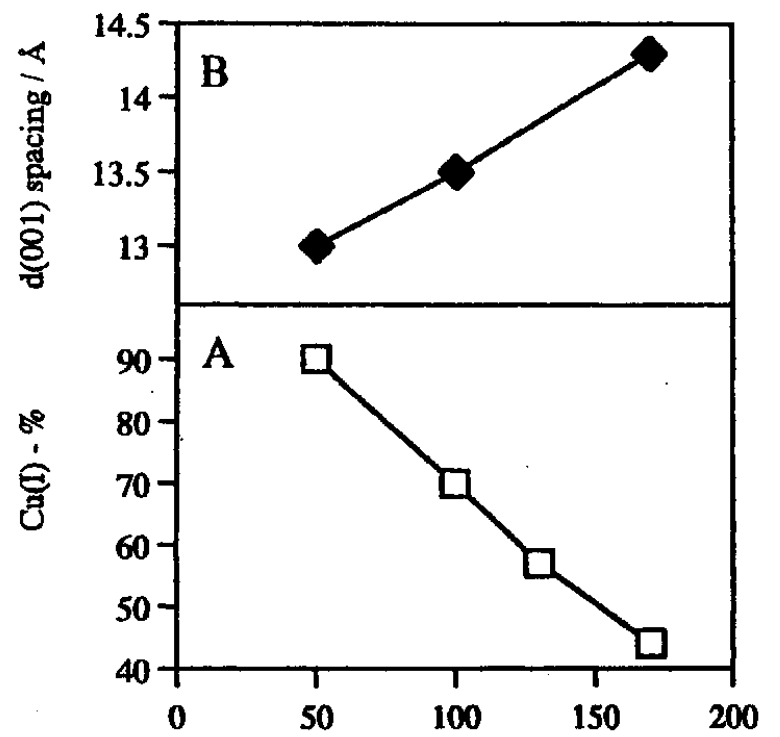

Loading $\mathrm{Cu} \phi_{2} / \%$ of CEC

Fig. 4 A: Change of photoreduction effect for $\mathrm{Cu}_{2} \mathrm{P}_{3 / 2}$ core line of [Cu(phen $\left.)_{2}\right]\left(\mathrm{NO}_{3}\right)_{2} \cdot \mathrm{H}_{2} \mathrm{O}$ in saponite. B: Change of basal $d(001)$ spacing of same samples as $A$.

\section{$\mathrm{Cu}(I I)$ complexes in saponite}

The photoreduction rate increased when $\mathrm{Cu}$ (II) complexes intercal ated into both montmorillonite and saponite. It is difficult to express exactly how much the photoreduction progresses. Though, a comparison of $2 \mathrm{p}_{3 / 2}$ peak areas of $\mathrm{Cu}(\mathrm{II})$ at $935 \mathrm{eV}$ and $\mathrm{Cu}(\mathrm{I})$ at 932.5 $\mathrm{eV}$ is possible on the assumption that the ratio of areas of $\mathrm{Cu}$ (II) main peak and its satellite is constant value, 1.65 , which is evaluated from the XPS spectrum of $\mathrm{CuO}$. A fraction of $\mathrm{Cu}(\mathrm{I})$ to total peak area, denoted as $\mathrm{Cu}(\mathrm{I})-\%$, would be proportional to the degree of photoreduction effect. It is interesting to see dependence of $\mathrm{Cu}(\mathrm{I})-\%$ on the loading amount of $\mathrm{Cu} \emptyset_{3}$ and $\mathrm{Cu} \emptyset_{2}$ in clay minerals.

The most typical result is obtained in the $\mathrm{Cu} \emptyset_{2}$-s aponite system. Figure 4 shows change of $\mathrm{Cu}(\mathrm{I})-\%$ and that of basal $\mathrm{d}(001)$ spacing as loading amount of $\mathrm{Cu}_{2}$ in saponite is varied When loading amount is $170 \%$ of CEC the clay mineral seems to have sufficient $d(001)$ spacing, $14.3 \AA$, for $C u \emptyset_{2}$ to exist without any structural stress, since the color of the treated clay mineral sample was green before $\mathrm{X}$-ray irradiation. This supports that $\mathrm{Cu} \emptyset_{2}$ keeps its original 5-coordinated structure. Circumstances were quite differentat $50 \%$ of CEC. The d(001) spacing of $13.0 \AA$ seems too small for a 5 coordinated structure to fit in the interl amellar space. In fact, the color of the treated clay mineral sample was pale blue and it suggests that the complex ion inside may have a tetragonally distorted 4-coordi nated structure. The plane of two phenanthroline molecule is expected to be parallel to phyllosilicate plane and $d_{z^{2}}$ orbital of the

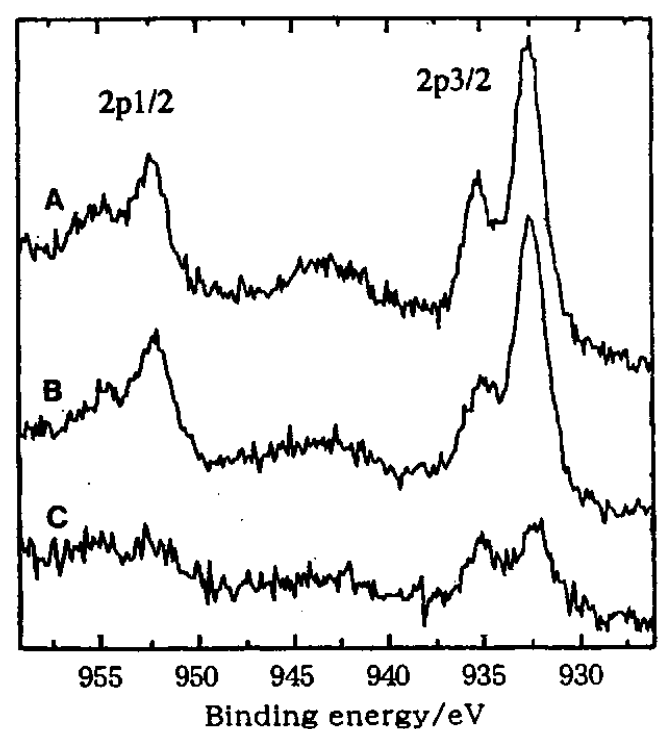

Fig. 5 XPS spectra of the $\mathrm{Cu} 2 \mathrm{p}$ for $[\mathrm{Cu}(\mathrm{phen}) 3] 2+$ in montmorill onite. Loading complex is (A) $50 \%$, (B) 100 $\%$, and (C) $130 \%$ of CEC of montmorillonite.

complex might point toward the plane. The structure of $\mathrm{Cu} \emptyset_{2}$ becomes less distorted as the loading amount of the complex increases since the basal spacing of the phyllosilicate becomes larger. As a result, in a distorted structure the photoreduction easily occurs.

Strong photoreduction effect was also recognized for $\mathrm{Cu} \emptyset_{3}$ in saponite. In saponite with $\mathrm{Cu}_{3}$ of $155 \%$ of $\mathrm{CEC}$, remaining $\mathrm{Cu}$ (II) $2 \mathrm{p}_{3 / 2}$ peak was regarded as only $30 \%$. For samples of $100 \%$ and $50 \%$ of $\mathrm{CEC}, \mathrm{Cu}(\mathrm{I})-\%$ seems to be $90-100 \%$ though they were measured only ambiguously because of low $S / N$ ratio. Roughly speaking, tendency is similar to the $\mathrm{Cu} \emptyset_{2}$-s aponite system. At $50 \%$ of CEC the basal spacing of saponite is $15.2 \AA$, which is smaller than that of montmorillonite, $(>17.7 \AA)$.

The observations for $\mathrm{Cu} \emptyset_{2}$ and $\mathrm{Cu} \emptyset_{3}$ in saponite indi cate that phyllosilicate layers of saponite interact each other strongly even when complex molecules are intercalated instead of exchangeable metal ions.

\section{$\mathrm{Cu} \emptyset_{3}$ in montmorillonite}

Figure 5 is XPS spectra of the $\mathrm{Cu} 2 \mathrm{p}$ for $\mathrm{Cu} \varnothing_{3}$ in montmonillonite. Photoreduction effect is observed but there seems no dependency on the loading amount of the complex. Even at $50 \%$ of $\mathrm{CEC}, \mathrm{Cu}$ (II) $2 \mathrm{p}_{3 / 2}$ core peak is clearly noticeable and $\mathrm{Cu}(\mathrm{I})-\%$ is rather less than those at higher \% of CEC. The XRD peak of basal $\mathrm{d}(001)$ spacing could not observed for all samples of this system, because of too low diffraction angle. The spacing, therefore, could estimated at least $17.7 \AA$. When a racemic mixture of $\left[\mathrm{Fe}(\text { phen })_{3}\right]^{2+}$ is absorbed by montmorillonite, a value of $29 \AA$ is given for basal d(001) spacing. ${ }^{3}$ It is 


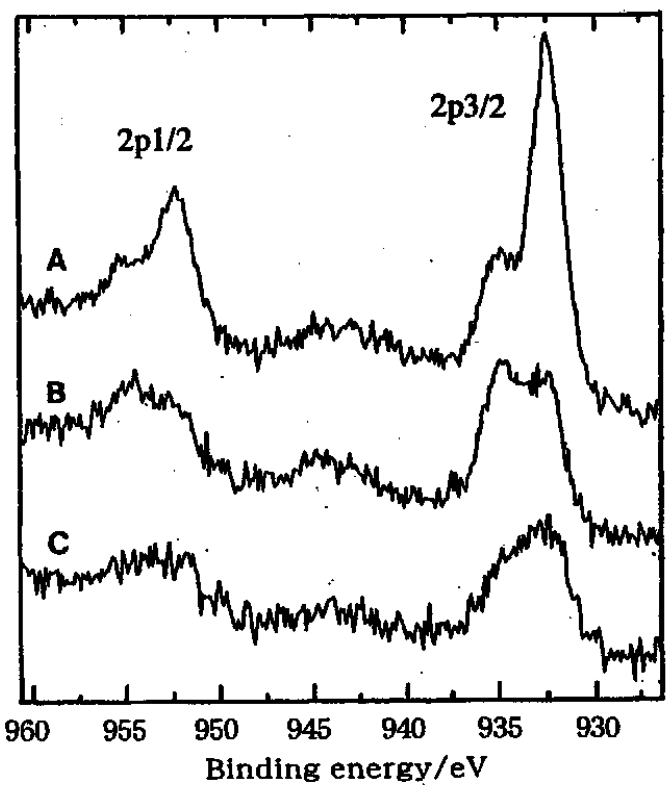

Fig. 6 XPS spectra of the Cu $2 p$ for $\left[\mathrm{Cu}(\mathrm{phen})_{2}\right]^{2+}$ in montmorillonite. Loading complex is, A: $50 \%$, B: $100 \%$, and C: $170 \%$ of CEC of montmorillonite.

suspected that the racemic aggregate is not a monomolecular layer but a double layer. It should be reasonable to assume that there are two distinguishable sites of the interlamellar $\mathrm{Cu} \varnothing_{3}$. The complex at one site would be easily reduced by $\mathrm{X}$-ray irradiation while at the other site photoreduction would not be so effective. When the latter site is predominant at lower \% of CEC the observation on XPS spectra of $\mathrm{Cu} 2 \mathrm{p}$ can be well explained.

\section{$\mathrm{Cu} \emptyset_{2}$ in montmorillonite}

All treated montmorillonite with $\mathrm{Cu} \varnothing_{2}$, from 130 to 50 $\%$ of CEC, exhibit same blue color and have an identical value of basal $\mathrm{d}(001)$ spacing of $15.5 \AA$. It should be considered that the interlamellar $\mathrm{Cu} \emptyset_{2}$ has a same structure in all samples but it is not the original 5-coordi nated one of which the color is green. The green saponite with the same complex of $170 \%$ of CEC have basal spacing of $14.3 \AA$, as already mentioned above. The blue $\mathrm{Cu} \varnothing_{2}$ in montmorillonite have probably 6-00ordinated structure and the interlamellar water molecule might be 6th ligand. This could explain larger $\mathrm{d}(001)$ value. Figure 6 shows the XPS spectra of $\mathrm{Cu}\left(\right.$ II) $2 p$ for $\mathrm{Cu}_{2}$ in montmorillonite. Three spectral patterns- look fairly different in the range between 930 and $940 \mathrm{eV}$. The difference is caused by broadening of the peak of $\mathrm{Cu}(\mathrm{I})$ 2p3/2 when loading amount of the complex is decreasing. $\mathrm{Cu}(\mathrm{l})$-\%, therefore, are regarded as more or less same, about $60-70 \%$. The broadening suggests that there are two or more structures of Cu(I) complex. Structural change is possible because $\mathrm{Cu}(\mathrm{I})$ preferrs 5 - or 4 coorinated structure instead of 6-coordnated Remaining of considerable $\mathrm{Cu}$ (II) peak at lower \% of CEC can be interpreted by two possible sites of 6-coordinated $\mathrm{Cu} \emptyset_{2}$ in a similar manner of $\mathrm{Cu} \emptyset_{3}$ in montmorillonite.

Professor Akihiko Yamagishi at Hokkaido University is gratefully acknowledged for his valuable suggestion at the beginning of the present work. Dr. Shin Koga of Kunimine Ind. Co. is also acknowledged for providing with clay minerals.

\section{References}

1. Y. Yano, T. Watanabe, M. Taniguchi and $A$. Yamagishi, Clay Sci., 8, 381(1992).

2. A. Yamagishi, J. Phys. Chem., 86, 2472 (1982).

3. A. Yamagishi, J. Coord. Chem., 16, 131 (1987).

4. T. Sudo, "Koubutu Kagaku (Chemistry of Minerals, in Japanese) II ", p.216, Kyoritu-shuppan, Tokyo, 1959.

5. C. Mosser, A. Mosser, M. Romeo, S. Petit and A. Decarreau, Clays \& Clay Minerals, 40, 593 (1992).

6. F. Parmigiani and L. E. Depero, Struct. Chem., 5, 117 (1994).

7. M. L. Farquhar, J. M. Charnock, K. E. R. England, and D. J. Vaughan, J. Colloid Interface Sci., 177, 561 (1996).

8. Y. Torii, "Shin Jikken Kagaku Koza (New Series of Experi mental Chemistry, in Japanese)", ed S. Nakahara and M. Shibata, vol. 8III, p.1476, 1492, 1977.

9. R. A. S. Schoonheydt, P. DePauw, D. Vliers and F. C. DeScrijver, J. Phys. Chem., 85, 5113 (1984). 